\title{
Human-Computer Interaction Perspective on Mobile Learning: Gender and Social Implications
}

\author{
https://doi.org/10.3991/ijim.v15i11.21367 \\ Ahmed Al-Hunaiyyan ${ }^{(凶)}$, Rana Alhajri \\ Public Authority for Applied Education and Training, \\ Kuwait City, Kuwait \\ aa.alhunaiyyan@paaet. edu. kw \\ Salah Al-Sharhan \\ College of North Atlantic, Doha, Qatar \\ Andrew Bimba \\ University Malaya, Kuala Lumpur, Malaysia
}

\begin{abstract}
The state of Kuwait has implemented a national e-learning initiative that included the distribution of mobile devices (Tablets) to be used by students and educators. Understanding the obstacles which currently prevent a successful roll-out, implementation, and adoption of mobile learning methods in Kuwait is vital. The opportunities for learners are particularly essential in this respect, and an absence of research remains an issue as far as Kuwait is concerned. This research was carried out within Kuwait Higher Education (HE) facilities to assess students' opinions and motivations for adopting this form of learning, aiming to analyse its efficacy and explore the social factors and gender issues that might impact extending mobile learning (m-learning) potential throughout Kuwait. A questionnaire has been central to this research, sent out to 620 students in total. Two statistical methods, an analysis of variance (ANOVA), and an independent-sample t-test, have been applied. The latter is essential for assessing if any statistical significance exists between two unrelated groups (male and female being the two independent variables). The results reveal disparities of age and gender while highlighting certain social and cultural factors that might prove to be obstacles that m-learning will need to overcome. A firm analysis of such issues will enable improved approaches to help learners' access and make the most robust m-learning methods.
\end{abstract}

Keywords - Mobile learning, e-learning, Human-Computer Interaction, Higher education, Gender differences

\section{Introduction}

Reliance on mobile devices is now felt in most elements of our daily lives, resulting in their utilisation throughout education programs - now referred to as mobile learning (m-learning). This concept is summarised as a learning dynamic that exists between 
students and their various resources, which are now obtainable remotely thanks to technological advances [1]. Adopting such technology to assist with their education has been robustly taken up by young Arab students [2]. Kuwait's Ministry of Education has implemented a national e-learning initiative which included the distribution of mobile devices (Tablets), to be used by students and educators [3]. In Kuwait, mobile technology sales have continued to grow without any sign of stopping [4]. The resulting accessibility, particularly among younger generations, together with quality infrastructure to support its use, means that Kuwait is well-placed to make the most of all mobile technology has to offer [5, 6]. Studies show that m-learning has numerous positives to offer in the development of creative endeavors, as well as in support for networking and the sharing of information and new ideas [7], however, very few educational applications which have been evaluated can promote intelligence and improve learning performance [8]. The main benefits of mobile learning, focusing on accessibility, privacy, the ability to merge, interactions, correspondence, speed, and universality [9]. With all the educational benefits provided by m-learning, the full adoption of this instructional method has been lacking in Kuwait. Understanding the obstacles which currently prevent a successful roll-out, implementation, and adoption of mobile learning methods in Kuwait is vital.

Human-computer interaction (HCI) focuses on how people approach and conduct their relationship with computers [10]; whereas mobile HCI concerns the intricacies of a person's relationship with a mobile system $[11,12]$. All the specific dynamics, which are liable to be impacted by cultural factors, may affect how the various systems, services, and mobile applications are applied. Important user features in this respect include character, cognitive preference, age, gender, and previous technology experience in both educational and social contexts [13]. Those involved in education, together with those who construct m-learning systems, would do well to adapt their current environments to account for various social contexts and gender differences, enhancing the learning potential $[14,15]$.

Gender is significant among many factors that affect how mobile phones are utilised, but it is essential to understand that culture may be just as crucial [16]. Prior studies have found both age and gender to impact people's approaches and habits when utilising technology $[6,17]$. Despite this, however, there is a lack of analysis of how personal attributes affect these behaviours as far as mobile learning in Kuwait is concerned. Examining such factors will enable us to devise more effective plans and schemes that help each learner to make their mark on enhancing learning programs and academic achievement $[18,19]$. Consequently, to speed up implementation throughout Kuwait, we consider it essential to assess learners' opinions and preferences regarding $\mathrm{m}$-learning potential and utilisation via an analysis of social and gender factors.

The research discussed here focuses on highlighting key aspects that impact learners ${ }^{6}$ habits and relationships with m-learning. We explore learners" interpretations of $\mathrm{m}$ learning's applicability in respect of age, gender, and social factors. In doing so, we consider it vital to comprehend the unique aspects involved by enhancing our appreciation of their perspectives of what m-learning can offer, together with becoming more conscious of barriers learners face due to social issues and problems related to educational facilities themselves. This research expands upon current mobile HCI 
knowledge by exploring learners' attributes and social dynamics that impact their perspectives of mobile technology potential. Plus, it provides a strategy for educational leaders to further utilise m-learning applications by merging approaches with the personal and social challenges that students face. This research was inspired by the possibility of examining how opinions and perspectives of mobile learning developed as a result which includes measuring its effectiveness, exploring age and gender-related factors, and social and cultural issues that may have had an impact. The aim of this research is to address the following questions:

- Do any important gender factors affect learners' utilisation of social media technology?

- Do any important age factors affect learners" utilisation of social media technology?

- Do any important gender factors affect learners' perceptions of m-learning?

- Do any important age differences affect learners" perceptions of m-learning?

The rest of the sections are set out as follows: Section 2 presents the associated studies on student's perspectives on Human-Computer Interaction (HCI) in different countries and subject matters. The third section presents the methodology used. It details the experimental samples and evaluation criteria. The results are put forward in Section 4, with the resulting discussion in Section 5. Finally, Section 6 offers conclusions and advice for future directions.

\section{Related Works}

Mobile human-computer interaction is understood as an analysis of the links between users and mobile technology, they use daily [20, 12]. As Ref. [9] describe, the user interface represents a central priority for companies working on advancing mobile technology, with details concerning robust interaction between various devices being detailed in the Human-Computer Interaction (HCI). Another study investigated English major students regarding the opinions and perspectives they had as a result of their experience at the College of Education in Kuwait [21]. Their findings showed that most learners were familiar $(80.3 \%)$ with how mobile technology can be incorporated to enhance the learning environment. In addition, they felt that access to m-learning improved their capabilities with grammar and vocabulary. Besides, Ref. [1] conducted survey research to assess the likelihood of merging m-learning with higher education (HE) facilities in Saudi Arabia. Their findings show how m-learning opens a range of potential that cannot be gained via other avenues, resulting in educational breakthroughs thanks to enhanced study methods and information gains.

Furthermore, Ref. [22] examined the effect of incorporating mobile technology among Saudi female HE educators. The results showed that the avoidance of adapting to new technology, together with recognised social structures, are essential for guiding the subsequent behaviours toward m-learning. Similar research carried out by Ref. [23] focused on analysing learners' attitudes toward m-learning among higher education facilities in Saudi Arabia. Applying quantitative methods, they completed a survey 
consisting of 80 learners enrolled in HE. The statistical analysis findings show the likelihood that Saudi learners will seek to embrace m-learning.

Research completed by Ref. [24] analysed how learners use smartphones as part of their coursework. Results were gathered from 77 learners at Lahti University of Applied Sciences in Finland. They highlighted how students tend to be very positive when $\mathrm{m}$ learning is incorporated into their coursework, making it an extra motivation for learners to study. Another research carried out by Ref. [25] endeavoured to analyse how learners consider mobile technology as ideal for enhancing and personalising their journey outside of the classroom. Fifty-three graduate students from a Central US University contributed to these findings, which show how m-learning can facilitate fresh learning experiences, enhancing learning potential, and encouraging learners to further their efforts in their free time. The study of Ref. [26] aimed to outline the use of $\mathrm{m}$-learning on different social groups. The study concludes that $\mathrm{m}$-learning provides refugees access to education.

Furthermore, the research of Ref. [27] focused on examining students' opinions and perspectives regarding mobile learning efficacy. The findings from a 100 -student survey carried out among Indian HE facilities showed that most learners see m-learning as essential for their educational journey. Furthermore, Ref. [28] explored learners ${ }^{6}$ attitudes toward mobile phones for learning by analysing socio-cultural factors that affect access and utilisation of the technology for learning. In doing so, they found that learners' positivity levels and enthusiasm for both individual and group learning improved.

\subsection{Gender and cultural influence on mobile HCI}

Concerning gender, extensive studies have focused on the contrasts between male and female learners regarding mobile technology use and incorporating national and cultural factors. The research of Ref. [29] for example, explored how male and female learners responded to a short message service (SMS), with results taken from 90 students in New Zealand. Their findings show that important variations exist with applicability and purpose while, in contrast, no such variations were found in relation to usability or personal competence with the technology. Additionally, Ref. [30] highlights gender disparities revealed by a cross-national examination of mobile technology applications using the examples of the USA, Sweden, Korea, and Japan. Data was assessed in the context of networking, correspondence issues, accessibility, and context management. The findings touch upon several topics related to attitude and gender-related factors. However, there is some indication that cultural issues are really at play. Similarly, the results of Ref. [12] revealed few differences between male and female students in their use of e-learning and their motivation and satisfaction.

Cultural variations concerning opinions and perspectives of technology can prove crucial for how they are embraced and applied to daily life and education $[31,32,17]$. Some studies concentrated on Saudi Arabia as a key example, where perceptions of gender are very much linked to cultural factors [33, 34]. Similarly, Ref. [35], endeavoured to identify the impact that cultural factors have on Instagram use in Kuwait by analysing the differences between male and female users. The findings highlight that 
men are more inclined to include personal content and photos, but a conservative culture holds back women from doing so.

\section{Methodology}

Various research has been carried out to determine the perceptions of students regarding $\mathrm{m}$-learning. These types of research are accomplished using a questionnaire to gather relevant information about the experimental sample, and a statistical method is used to determine the significance of the outcome. To explore the effect of age, gender-related factors, social and cultural issues that may have impacted the adoption of m-learning in Kuwait, a questionnaire and Analysis of Variance (ANOVA) was utilised. The one-way ANOVA helps to determine if there are any significant differences between the independent variables such as gender and age.

\subsection{Evaluation instrument}

A questionnaire was set up based on several previous studies and made available online $[21,36,3]$. Crucially, the questions posed and the measurement scales were customised to remain specific to this research. There are three sections to the questionnaire. Section 1 obtains the vital learner data, such as age and gender. Part 2 explores the regularity of learners" utilisation of various social media - achieved using the four scales of 'Always," 'Sometimes," 'Rare,' and 'I don't use it.' Both age and gender were included as important factors: part 3 concerns learners' opinions and behaviours in respect to mobile technology potential and social media usage. Eight questions make up this section in total, which also employs a Five Point Likert scale as follows: 1 for Strongly Disagree, 2 for Disagree, 3 for Neutral, 4 for Agree, and 5 for Strongly Agree. As Tables 4 and 5 show, the first three questions analyse learners opinions of m-learning. Questions four and five moves on to their perspectives regarding social media flexibility incorporated into their learning journey. Finally, the remaining three questions examine cultural and social factors that impact the embracing of m-learning and social media. Before the study was underway, a preparatory pilot study took place that included 20 students. This was completed to establish the research's viability and iron out any issues, refining questions where possible and assessing whether the results returned the required information. As a result, some questions were reworded for clarity. The reliability of the questionnaire has been calculated by finding Cronbach's alpha by using SPSS. The total score of Cronbach's Alpha is (0.92). The questionnaire can be generalised to the primary study sample, and the results can be trusted.

Two statistical methods, an analysis of variance (ANOVA), and an independentsample t-test, have been applied. The latter is essential for assessing if any statistical significance exists between two unrelated groups (male and female being the two independent variables). Utilising One-Way ANOVA allows for comparisons between three or more groups and variables, offering contrasts with statistical significance means (with the three age groups making up the independent variables). As this data is 
parametric in form, ANOVA and t-test have been chosen for their applicability in respect of interval scale features. A significance level of 0.05 was taken for all cases, with statistical analysis being applied to ensure there is no subjectivity in the assessment of variables.

\subsection{Sample}

All contributors to this research were learners being educated at a range of Kuwaiti HE facilities, selected to account for institutions from both the public and private sectors. Once communication was in place, the online questionnaire was randomly distributed with both male and female respondents making up the 620 contributors. The study's authors, who are attributed with both public and private Kuwaiti HE facilities, oversaw the online distribution via email and social media avenues. Responses were then gathered for assessment one week after the initial roll-out via the survey monkey application. Four hundred ninety-nine valid responses were recognised in total and applied to the statistical analysis, with this number made up of 339 females and 160 males. The age groups represented included 336 respondents in the 16-24 years age group, 116 in the $25-35$ years age group, and 47 above 35 years old. The differences apparent between variables were analysed objectively using statistical analysis.

\section{$4 \quad$ Results}

\subsection{Respondents' ${ }^{6}$ demographic data}

Table 1 shows the respondents" demographics, with male and female respondents categorised as per their age groups:' $16-24$, ' ' $25-35$, ' and 'over 35 years.'

Table 1. Students' Gender and Age

\begin{tabular}{|l|c|c|c|c|}
\hline \multirow{2}{*}{ Gender } & \multicolumn{3}{|c|}{ Age } & \multirow{2}{*}{ Total } \\
\cline { 2 - 4 } & $\mathbf{1 6 - 2 4}$ & $\mathbf{2 5 - 3 5}$ & More than 35 & \\
\hline Male & 118 & 36 & 6 & 160 \\
\hline Female & 218 & 80 & 41 & 339 \\
\hline Total & 336 & 116 & 47 & 499 \\
\hline
\end{tabular}

\subsection{Students' regular use of social media technology}

Section 2 of the questionnaire explores learner's regular access to social media, particularly via popular applications like Facebook, Twitter, Instagram, YouTube, LinkedIn, and Snapchat. Examining the responses allowed us to identify any significant differences in how these applications are utilised. The results related to gender recorded in Table 2 and those of age recorded in Table 3.

Concerning gender, by applying a t-test, Table 2 figures show that no significant difference can be detected as far as Twitter goes: 'significance level' $(\mathrm{p}=0.113)$ or Instagram $(\mathrm{p}=0.487)$. In contrast to this, the other social media applications do record 
significant differences between Facebook $(\mathrm{p}=0.000)$, YouTube $(\mathrm{p}=0.001)$, Snapchat $(p=0.010)$, and LinkedIn $(p=0.000)$. Furthermore, by assessing the mean values, we find that men are more inclined to use Facebook, YouTube, and LinkedIn than women, but women are more likely to utilise Snapchat.

Utilising One-Way ANOVA allows us to assess the Table 3 results, which find no significant differences as far as the three age groups are concerned for the following social media applications: Twitter $(\mathrm{p}=0.443)$, Instagram $(\mathrm{p}=0.248)$, and LinkedIn $(\mathrm{p}=0.124)$. In contrast, however, the results show that significant differences are apparent for the other three social media applications, as follows: Facebook $(\mathrm{p}=0.006)$, YouTube $(\mathrm{p}=0.017)$, and Snapchat $(\mathrm{p}=0.000)$. Nevertheless, the results also highlight that there is no enthusiasm for Facebook among the three age groups. Still, there is an inclination among the youngest group to embrace Snapchat and YouTube.

Irrespective of the age and gender of respondents, when the mean values are taken from highest to lowest the results are as follows: YouTube, Snapchat, Instagram, Twitter, Facebook, and LinkedIn.

Table 2. Learners‘ Social Media Application Use (Gender Differences)

\begin{tabular}{|c|c|c|c|c|c|c|c|c|}
\hline $\begin{array}{c}\text { Social Media } \\
\text { Application }\end{array}$ & Gender & Always & Sometimes & Rare & Do not use & Mean & SD & Sig. \\
\hline \multirow{2}{*}{ Twitter } & Male & 47 & 50 & 31 & 32 & 2.70 & 1.098 & \multirow{2}{*}{0.133} \\
\hline & Female & 93 & 95 & 63 & 88 & 2.57 & 1.148 & \\
\hline \multirow{2}{*}{ Instagram } & Male & 76 & 57 & 16 & 11 & 3.24 & .894 & \multirow{2}{*}{0.487} \\
\hline & Female & 148 & 133 & 39 & 19 & 3.21 & .857 & \\
\hline \multirow{2}{*}{ Facebook } & Male & 14 & 17 & 33 & 96 & 1.68 & .980 & \multirow{2}{*}{0.000} \\
\hline & Female & 13 & 23 & 40 & 263 & 1.37 & .775 & \\
\hline \multirow{2}{*}{ YouTube } & Male & 112 & 41 & 6 & 1 & 3.65 & .585 & \multirow{2}{*}{0.001} \\
\hline & Female & 193 & 121 & 18 & 7 & 3.47 & .693 & \\
\hline \multirow{2}{*}{ Snapchat } & Male & 101 & 22 & 15 & 22 & 3.26 & 1.102 & \multirow{2}{*}{0.010} \\
\hline & Female & 253 & 37 & 8 & 41 & 3.48 & 1.013 & \\
\hline \multirow{2}{*}{ LinkedIn } & Male & 4 & 12 & 9 & 135 & 1.28 & .711 & \multirow{2}{*}{0.000} \\
\hline & Female & 2 & 8 & 19 & 310 & 1.12 & .435 & \\
\hline
\end{tabular}


Table 3. Learners' Social Media Application Use (Age Differences)

\begin{tabular}{|c|c|c|c|c|c|c|c|c|}
\hline $\begin{array}{c}\text { Social Media } \\
\text { Application }\end{array}$ & Age & Always & Sometimes & Rare & Do not use & Mean & SD & Sig. \\
\hline \multirow{3}{*}{ Twitter } & $16-24$ & 98 & 96 & 67 & 75 & 2.65 & 1.123 & \multirow{3}{*}{.443} \\
\hline & $25-35$ & 31 & 36 & 19 & 30 & 2.59 & 1.143 & \\
\hline & $>35$ & 11 & 13 & 8 & 15 & 2.43 & 1.175 & \\
\hline \multirow{3}{*}{ Instagram } & $16-24$ & 145 & 136 & 38 & 17 & 3.22 & .838 & \multirow{3}{*}{.248} \\
\hline & $25-35$ & 62 & 34 & 12 & 8 & 3.29 & .914 & \\
\hline & $>35$ & 17 & 20 & 5 & 5 & 3.04 & .955 & \\
\hline \multirow{3}{*}{ Facebook } & $16-24$ & 12 & 25 & 51 & 248 & 1.41 & .779 & \multirow{3}{*}{.006} \\
\hline & $25-35$ & 8 & 10 & 14 & 84 & 1.50 & .918 & \\
\hline & $>35$ & 7 & 5 & 8 & 27 & 1.83 & 1.129 & \\
\hline \multirow{3}{*}{ YouTube } & $16-24$ & 215 & 102 & 15 & 4 & 3.57 & .638 & \multirow{3}{*}{.017} \\
\hline & \begin{tabular}{|l|}
$25-35$ \\
\end{tabular} & 69 & 40 & 5 & 2 & 3.52 & .666 & \\
\hline & $>35$ & 21 & 20 & 4 & 2 & 3.28 & .800 & \\
\hline \multirow{3}{*}{ Snapchat } & 16-24 & 255 & 37 & 12 & 32 & 3.53 & .946 & \multirow{3}{*}{.000} \\
\hline & $25-35$ & 81 & 12 & 7 & 16 & 3.36 & 1.091 & \\
\hline & $>35$ & 18 & 10 & 4 & 15 & 2.66 & 1.290 & \\
\hline \multirow{3}{*}{ LinkedIn } & $16-24$ & 4 & 9 & 17 & 306 & 1.14 & .496 & \multirow{3}{*}{.124} \\
\hline & $25-35$ & 2 & 8 & 8 & 98 & 1.26 & .661 & \\
\hline & $>35$ & 0 & 3 & 3 & 41 & 1.19 & .537 & \\
\hline
\end{tabular}

\subsection{Learners' $\mathrm{m}$-learning perspectives}

Section 3 of the questionnaire focuses on learners' opinions and perspectives of $\mathrm{m}$ learning, with Table 4 showcasing their responses regarding gender, and Table 5 in respect of age. By utilising a t-test, Table 4 findings reveal no significant differences between genders concerning opinions held toward m-learning or the benefits of social media applications. Assessing the mean values of questions 1-5 allows for recognising that learners possess positive perceptions of m-learning potential without gender showing any fluctuation.

Moving on to Questions 6, 7, and 8, we can analyse learners' opinions of social and cultural factors influencing m-learning and the use of social media. From Question 6, the results record a neutral position about male and female learners being able to contact each other using m-learning technology. Although among those who do show rejection, the scores are higher for males (3.09) than females (2.96). Likewise, Question 7, "Will society reject m-learning due to customs and traditions?" also finds neutrality. However, when comparing males' perspectives with females, the latter is shown as higher (2.90 versus 2.82). Plus, when posed the question of whether social media applications are likely to have a negative impact on family life, the findings were also neutral. Still, again female perspectives were scored higher (3.31 versus 3.09). 
Table 4. Students' Perceptions of M-learning: (Gender Differences) - t-test

\begin{tabular}{|c|c|c|c|c|c|c|c|c|c|c|}
\hline & Question & Gender & $\begin{array}{c}\text { Strongly } \\
\text { Agree }\end{array}$ & Agree & Neutral & Disagree & \begin{tabular}{|l|} 
Strongly \\
Disagree
\end{tabular} & Mean & SD & Sig. \\
\hline \multirow[b]{2}{*}{ Q1 } & \multirow{2}{*}{$\begin{array}{l}\text { Learning by } \\
\text { mobile increases } \\
\text { students' } \\
\text { motivation }\end{array}$} & Male & 42 & 46 & 49 & 16 & 7 & 3.63 & 1.109 & \multirow[b]{2}{*}{.885} \\
\hline & & Female & 85 & 104 & 91 & 48 & 11 & 3.60 & 1.106 & \\
\hline \multirow[b]{2}{*}{ Q2 } & \multirow{2}{*}{$\begin{array}{l}\text { I believe that } \\
\text { learning by } \\
\text { mobile is a great } \\
\text { idea }\end{array}$} & Male & 47 & 50 & 40 & 12 & 11 & 3.69 & 1.172 & \multirow[b]{2}{*}{.773} \\
\hline & & Female & 97 & 111 & 77 & 38 & 16 & 3.69 & 1.138 & \\
\hline \multirow[b]{2}{*}{ Q3 } & \multirow{2}{*}{$\begin{array}{l}\text { M-learning } \\
\text { increases } \\
\text { students' and } \\
\text { instructors' } \\
\text { interactions }\end{array}$} & Male & 63 & 57 & 30 & 4 & 6 & 4.04 & 1.012 & \multirow[b]{2}{*}{.581} \\
\hline & & Female & 120 & 135 & 54 & 22 & 8 & 3.99 & .994 & \\
\hline \multirow[b]{2}{*}{ Q4 } & \multirow{2}{*}{$\begin{array}{l}\text { Social media } \\
\text { applications help } \\
\text { in educational } \\
\text { attainment }\end{array}$} & Male & 49 & 67 & 30 & 8 & 6 & 3.91 & 1.014 & \multirow[b]{2}{*}{.168} \\
\hline & & Female & 70 & 153 & 65 & 40 & 11 & 3.68 & 1.031 & \\
\hline \multirow[b]{2}{*}{ Q5 } & \multirow{2}{*}{$\begin{array}{l}\text { Social media } \\
\text { helps to } \\
\text { strengthen } \\
\text { communication } \\
\text { with instructors } \\
\text { and students } \\
\end{array}$} & Male & 72 & 57 & 19 & 3 & 9 & 4.13 & 1.068 & \multirow[b]{2}{*}{.184} \\
\hline & & Female & 134 & 143 & 35 & 20 & 7 & 4.11 & .954 & \\
\hline & \multirow{2}{*}{$\begin{array}{l}\text { I reject m- } \\
\text { learning if it } \\
\text { allows male and } \\
\text { female students } \\
\text { to contact each } \\
\text { other }\end{array}$} & Male & 28 & 30 & 55 & 22 & 25 & 3.09 & 1.286 & \multirow[b]{2}{*}{.586} \\
\hline Q6 & & Female & 46 & 65 & 106 & 75 & 47 & 2.96 & 1.230 & \\
\hline \multirow[b]{2}{*}{ Q7 } & \multirow{2}{*}{$\begin{array}{l}\text { Our society will } \\
\text { reject m-learning } \\
\text { because of our } \\
\text { customs and } \\
\text { traditions }\end{array}$} & Male & 12 & 34 & 57 & 27 & 30 & 2.82 & 1.186 & \multirow[b]{2}{*}{.701} \\
\hline & & Female & 37 & 63 & 110 & 87 & 42 & 2.90 & 1.170 & \\
\hline \multirow[b]{2}{*}{ Q8 } & \multirow{2}{*}{$\begin{array}{l}\text { The use of social } \\
\text { media will cause } \\
\text { social and family } \\
\text { problems }\end{array}$} & Male & 21 & 39 & 52 & 30 & 18 & 3.09 & 1.186 & \multirow[b]{2}{*}{.890} \\
\hline & & Female & 54 & 97 & 110 & 56 & 22 & 3.31 & 1.121 & \\
\hline
\end{tabular}

To assess the results regarding age, a One-Way ANOVA test on questions 1- 6 (as per Table 5), finds no significant differences in m-learning potential or social media utilisation due to age. With an examination of the mean values that resulted, we can ascertain that age does not play a significant factor in learners' developing positive perspectives about the applicability of m-learning.

In contrast, differences do emerge when we consider Questions 7 and 8, which show the age group's differing responses. When answering Question 7, which asked whether cultural habits might obstruct access to m-learning, a neutral result was recorded. However, adults over 35 years of age had a mean score of 3.32, which was slightly higher than the younger age groups. Plus, Question 8 were also neutral in seeing social media as leading to possible issues within the family. However, the results show more 
agreement among older adults, with a mean of 3.62 for the 35 years and more age group and 3.53 for the 25-35 years age group, compared to 3.09 for the 16-24 years age group.

Table 5. Students“ Perception of M-learning: (Age Differences) - ANOVA test

\begin{tabular}{|c|c|c|c|c|c|c|c|c|c|c|}
\hline & Questions & Age & $\begin{array}{c}\text { Strongly } \\
\text { Agree }\end{array}$ & Agree & Neutral & Disagree & $\begin{array}{l}\text { Strongly } \\
\text { Disagree }\end{array}$ & Mean & SD & Sig. \\
\hline \multirow{3}{*}{ Q1 } & \multirow{3}{*}{$\begin{array}{l}\text { Learning by mobile } \\
\text { increases students، } \\
\text { motivation. }\end{array}$} & $16-24$ & 90 & 93 & 101 & 41 & 11 & 3.63 & 1.102 & \multirow{3}{*}{.404} \\
\hline & & $25-35$ & 31 & 38 & 28 & 13 & 6 & 3.65 & 1.144 & \\
\hline & & $>35$ & 6 & 19 & 11 & 10 & 1 & 3.40 & 1.035 & \\
\hline \multirow{3}{*}{ Q2 } & \multirow{3}{*}{$\begin{array}{l}\text { I believe that learning by } \\
\text { mobile is a great idea }\end{array}$} & $16-24$ & 102 & 105 & 84 & 29 & 16 & 3.74 & 1.124 & \multirow{3}{*}{.084} \\
\hline & & $25-35$ & 35 & 38 & 23 & 13 & 7 & 3.70 & 1.188 & \\
\hline & & $>35$ & 7 & 18 & 10 & 8 & 4 & 3.34 & 1.185 & \\
\hline \multirow{3}{*}{ Q3 } & \multirow{3}{*}{$\begin{array}{l}\text { M-learning increases } \\
\text { students' and instructors' } \\
\text { interactions }\end{array}$} & $16-24$ & 134 & 119 & 60 & 14 & 9 & 4.06 & .992 & \multirow{3}{*}{.062} \\
\hline & & $25-35$ & 42 & 49 & 17 & 6 & 2 & 4.06 & .935 & \\
\hline & & $>35$ & 7 & 24 & 7 & 6 & 3 & 3.55 & 1.100 & \\
\hline \multirow{3}{*}{ Q4 } & \multirow{3}{*}{$\begin{array}{l}\text { Social media applications } \\
\text { help in educational } \\
\text { attainment }\end{array}$} & $16-24$ & 80 & 149 & 73 & 25 & 9 & 3.79 & .976 & \multirow{3}{*}{.071} \\
\hline & & $25-35$ & 30 & 53 & 15 & 13 & 5 & 3.78 & 1.088 & \\
\hline & & $>35$ & 9 & 18 & 7 & 10 & 3 & 3.43 & 1.211 & \\
\hline \multirow{3}{*}{ Q5 } & \multirow{3}{*}{$\begin{array}{l}\text { Social media helps to } \\
\text { strengthen } \\
\text { communication with } \\
\text { instructors and students } \\
\end{array}$} & $16-24$ & 146 & 128 & 39 & 14 & 9 & 4.15 & .968 & \multirow{3}{*}{.144} \\
\hline & & $25-35$ & 49 & 46 & 9 & 9 & 3 & 4.11 & 1.020 & \\
\hline & & $>35$ & 11 & 26 & 6 & 0 & 4 & 3.85 & 1.063 & \\
\hline \multirow{3}{*}{ Q6 } & \multirow{3}{*}{$\begin{array}{l}\text { I reject m-learning if it } \\
\text { allows male and female } \\
\text { students to contact each } \\
\text { other }\end{array}$} & $16-24$ & 53 & 60 & 117 & 61 & 45 & 3.04 & 1.237 & \multirow{3}{*}{.327} \\
\hline & & $25-35$ & 14 & 21 & 35 & 26 & 20 & 2.85 & 1.253 & \\
\hline & & $>35$ & 7 & 14 & 9 & 10 & 7 & 3.09 & 1.316 & \\
\hline \multirow{3}{*}{ Q7 } & \multirow{3}{*}{$\begin{array}{l}\text { Our society will reject m- } \\
\text { learning because of our } \\
\text { customs and traditions }\end{array}$} & $16-24$ & 32 & 63 & 111 & 77 & 53 & 2.83 & 1.185 & \multirow{3}{*}{.023} \\
\hline & & $25-35$ & 7 & 23 & 43 & 27 & 16 & 2.81 & 1.095 & \\
\hline & & $>35$ & 10 & 11 & 13 & 10 & 3 & 3.32 & 1.218 & \\
\hline \multirow{3}{*}{ Q8 } & \multirow{3}{*}{$\begin{array}{l}\text { The use of social media } \\
\text { will cause social and } \\
\text { family problems }\end{array}$} & $16-24$ & 37 & 85 & 116 & 66 & 32 & 3.09 & 1.126 & \multirow{3}{*}{.000} \\
\hline & & $25-35$ & 28 & 32 & 37 & 12 & 7 & 3.53 & 1.145 & \\
\hline & & $>35$ & 10 & 19 & 9 & 8 & 1 & 3.62 & 1.074 & \\
\hline
\end{tabular}

\section{Discussions}

This study aims to analyse how learners in Kuwait view m-learning and utilising social media for education, which is explored in respect to age and gender while appreciating the crucial social and cultural factors involved. Social media developments have resulted in mobile technology becoming ever more versatile and relevant, offering greater learning benefits and providing fresh avenues for furthering learners“ networking, teamwork, and overall dynamism [37]. Social media to have extended students' abilities to achieve collaborative learning methods, so they can now advance their thinking collectively [38], enhancing computational thinking (CT), and developing students coding skills [39, 40]. Consequently, we examined learners“ adoption of social media technology to appreciate the features and application that are most enthusiastically embraced. Doing so offers those involved with education an 
overview of how learners' can be reached and further inspired due to their mobile device capabilities.

In answering the question: "Do any important gender factors affect learners" utilisation of social media technology?" The findings suggest that no substantial difference is present between male and female learners in terms of Instagram or Twitter use. Nevertheless, some differences are apparent between the genders concerning the other widely used social media sites of YouTube, Facebook, LinkedIn, and Snapchat. In this regard, female learners are more inclined to use Snapchat, whereas male learners prefer YouTube, Facebook, and LinkedIn.

Moving on to the second question, "Do any important age factors affect learners" utilisation of social media technology?" The results suggest that no substantial differences exist because of the student age groups as far as Instagram, Twitter, and LinkedIn are concerned. On the other hand, differences are apparent regarding the usage of YouTube, Facebook, and Snapchat. Our study did not identify a particular enthusiasm for Facebook in an educational sense, but younger students (16-24 years old) favour YouTube and Snapchat for these purposes. Plus, learners show little enthusiasm for LinkedIn either, which likely suggests a lack of engagement with these specific tools designed for professional contexts.

Furthermore, the signs are that both Facebook and LinkedIn are losing their attraction to younger generations who are much more used to the interactive nature and versatility of Snapchat and Instagram [41]. It is an intriguing result to recognise that male and female learners of all ages utilise Snapchat and YouTube, but females are attracted to Snapchat. The likelihood is that the lack of any history files on Snapchat removes any paranoia that something negative might be revealed. In comparison, male learners are more inclined to utilise YouTube.

Analysing learners' regular use of social media technology can further support the pinpointing of new methods that professionals can embrace to further enhance mlearning potential. Consequently, those professionals concerned with the advancement of m-learning products would also do well to appreciate how learners make the most of the likes of YouTube, Snapchat, and Instagram.

Moving on to the third question, "Do any important gender factors affect learners" perceptions of m-learning?", together with the fourth, "Do any important age differences affect learners" perceptions of m-learning?" Our findings reveal no substantial differences between the genders or age groups regarding attitudes toward $\mathrm{m}$-learning potential and social media technology. Therefore, both genders and younger and mature students take an optimistic approach to m-learning and what they can gain from its use. Learners consider mobile technology to offer a range of benefits, recognise that they are extra motivated by its presence, strengthen connections with educators, and overcomes issues of time and location. Students also consider social media technology to be central to overall educational achievement and improve the collaborations they can conduct with fellow learners and tutors.

While we have studied gender as one crucial factor in how students utilise mobile technology, it remains essential to recognise that social and cultural habits may also be vital. This research has identified notable age disparities concerning those questions of social and cultural factors - Questions 7 and 8 "Our society will reject m-learning 
because of our customs and traditions" and "The use of social media will cause social and family problems." For these factors, it is vital to appreciate the conservative habits and traditions of Kuwaiti life and recognise that male and female learners are separated in the country's education system. As a result, learners' perspectives on male and female correspondence via m-learning features tend to reflect wider societal views. These findings were particularly clear in students belonging to the mature age group, who consider social media as potentially more problematic on a social level than the younger age groups that took part.

Research carried out by Ref. [35] endeavoured to assess the impact that culture has on how both genders utilise Instagram. The findings attest that males feel the more comfortable of the two as far as their own photos and information are concerned. Along similar lines, Ref. [33] explores how cultural habits within Saudi Arabia come to dictate behaviours according to gender. Due to traditions drawn from faith and culture, Saudi educational facilities are structured based on gender segregation, which inevitably affects people's actions and opinions. Other studies align with ours in this regard as, regardless of how m-learning is embraced and the optimism associated with its potential shown by both genders and all age groups, Kuwaiti users do remain held back by social and cultural dilemmas [18]. Getting to grips with these challenges is asking difficult cultural questions, which may be approached differently by different age groups. Therefore, M-learning developers are tasked with results that aid such dilemmas - most of whom are from younger age groups themselves [11], having in mind that many educational applications developed for mobile devices were not designed and developed in a way to encourage young students to use technology to promote optimal development [42].

In this research, the perceptions of the student's cannot be fully adopted. This is a limitation because mobile learning has not been fully embedded within the HE in Kuwait, even though students utilise mobile learning in education. In the series of questions from the survey, students indicated having trouble maintaining sufficient levels of time and effort to complete the questionnaire. This was because of slow internet connectivity and not having access to software such as Microsoft Word.

\section{Conclusion and Future Directions}

Mobile HCI echoes its users' attributes, including their age and genders, cognitive ability, character, and learning potential. A student's characteristics may impact their impression of and opinions toward the utilisation of mobile learning on a social level. The purpose of conducting this research is to gain a clearer picture of learners' opinions and perspectives on m-learning via the related social factors and gender dynamics present in Kuwaiti facilities.

The findings further our understanding of mobile HCI by analysing the key student's attributes and social features that direct their learning approach via mobile technology. The results indicate that most learners consider this approach positively due to the versatility it offers in terms of time and location, which gender or age do not have to restrict them from. 
Nevertheless, regardless of this positivity, students show caution due to the mlearning and social media use, potentially allowing more correspondence between them. The findings explored, however, do show less of this caution among the younger students. So, as Kuwait continues to progress, new generations might develop and embrace different attitudes toward m-learning. The results also show notable age and gender differences, with evidence that cultural and social factors serve as obstacles to $\mathrm{m}$-learning application. Consequently, this study furthers the previous findings on gender dynamics in this context. Gaining firmer knowledge of the issues involved might inform more robust strategies supporting students in accessing improved learning practices.

Despite education professions already being familiar with m-learning utilisation, current class strategies could still benefit from being upgraded to suit gender dynamics and social structures, furthering their applicability for all students relying on mobile technology. The approach that each student will take remains reliant on their own connection with mobile technology. This means that professionals looking up to upgrade their teaching practices by merging further with mobile technology need to do so in a manner that addresses cultural dynamics concerning gender and the social factors that might prove restrictive. As far as Kuwaiti higher education institutes are concerned, the utilisation of m-learning is still in its early stages. However, with the right knowledge and appreciation of the challenges involved, professionals and their related policymakers should upgrade methods and environments to help their students thrive despite factors related to social and cultural issues or reliance on established traditions. The results reveal disparities of age and gender while highlighting certain social and cultural factors that might prove to be obstacles that m-learning will need to overcome.

Regarding the potential for further studies, our advice would be to delve further into other cultural and social dynamics that might hold individuals back from embracing $\mathrm{m}$ learning potential and produce former advice for education professionals and product developers. A thorough examination of students' many attributes might lead to numerous breakthroughs in how m-learning can be supported in a more fulfilling, agreeable, and interactive way.

Furthermore, greater access to open educational resources that complement mlearning potential is proving more cost-effective for learners. Additional studies of how the design and presentation of learning resources via mobile devices, in respect of Arab culture dynamics, might prove vital for merging with academic strategies at the same time as appreciating the many different qualities, ethics, and backgrounds that students possess.

\section{$7 \quad$ References}

[1] S. Almutairy, T. Davies and W. Dimitriadi, "The Readiness of Applying M-Learning among Saudi Arabian Students at Higher Education," International Journal of Interactive Mobile Technologies iJIM, vol. 9, no. 3, pp. 33-36, 2015. https://doi.org/10.3991/ijim.v9i3.4423 
[2] S. Al-Shehri, "Contextual language learning: The educational potential of mobile technologies and social media. (Doctoral Dissertation)," The University of Queensland, Australia, 2012.

[3] A. Al-Hunaiyyan, S. Al-Sharhan and R. Al-Hajri, "Prospects and Challenges of Learning Management Systems in Higher Education," International Journal of Advanced Computer Science and Applications (IJACSA), Vol. 11, No. 12, pp. 73-79, 2020. https://doi.org/10.14569/IJACSA.2020.0111209

[4] Kuwait Telecommunications Report, "Kuwait - Telecoms, Mobile and Broadband Statistics and Analyses - Quarter 1," Kuwait, 2021.

[5] A. Al-Hunaiyyan, A. Al-Sharhan and R. Alhajri, "A New Mobile Learning Model in the Context of the Smart Classrooms Environment: A Holistic Approach,” International Journal of Interactive Mobile Technologies (iJIM). Vol.11_No.3(2017), pp. 39-56, 2017. https://doi.org/10.3991/ijim.v11i3.6186

[6] A. Al-hunaiyyan, S. Al-Sharhan and R. Alhajri, "Instructors Age and Gender Differences in the Acceptance of Mobile Learning," International Journal of Interactive Mobile Technologies (iJIM). Vol. 11, No. 4, 2017 B. https://doi.org/10.3991/ijim.v11i4.6185

[7] A. K. Alhazmi, A. A. Rahman and H. Zafar, "Conceptual model for the academic use of Social Networking Sites from student engagement perspective," in 2014 IEEE Conference on e-Learning, e-Management and e-Services (IC3e 2014), Melbourne, Australia 10-12 December 2014, 2014. https://doi.org/10.1109/IC3e.2014.7081232

[8] S. Papadakis and M. Kalogiannakis, "A research synthesis of the real value of selfproclaimed mobile educational applications for young children," in Mobile learning applications in early childhood education, 2020, pp. 1-19. https://doi.org/10.4018/978-17998-1486-3.ch001

[9] S. Tabrizi and N. Cavus, "HCI Standards For Developing Mobile Learning Applications in Education," in INTED2017 Proceedings, 6-8 March, 2017, Valencia, Spain, 2017. https://doi.org/10.21125/inted.2017.1504

[10] A. Dix, J. Finlay, G. Abowd and R. Beale, Human-computer interaction, 3rd ed., New York: Prentice Hall, 2003.

[11] A. Jenkins, P. Eslambolchilar, S. Lindsay , M. Hare , I. Thornton and A. Tale, "Attitudes towards Attention and Aging: What Differences between Younger and Older Adults Tell Us about Mobile Technology Design," International Journal of Mobile Human Computer Interaction (IJMHCI) 8(2), pp. PP. 47-68, 2016. https://doi.org/10.4018/IJMHCI.20160 40103

[12] M. Cuadrado-Garcia, M. Ruiz-Molina and J. Montoro-Pons, "Cuadrado-Garcia, Manuel \& Ruiz-Molina, Maria \& Montoro-Pons, Juan. (2010). Are there gender differences in elearning use and assessment? Evidence from an interuniversity online project in Europe," Procedia - Social and Behavioral Sciences, pp. 367-371, 2010. https://doi.org/10.1016/ j.sbspro.2010.03.027

[13] R. AlHajri, S. Al-Sharhan, A. Al-Hunaiyyan and T. Alothman, "Design of educational multimedia interfaces: individual differences of learners," in Proceedings of the Second Kuwait Conference on e-Services and e-Systems, Kuwait, 2011. https://doi.org/10.1145/ 2107556.2107568

[14] R. Alhajri and A. Al-Hunaiyyan, "Integrating Learning Style in the Design of Educational Interfaces," ACSIJ Advances in Computer Science: an International Journal, Vol. 5, Issue 1, No.19, January 2016. ISSN : 2322-5157, 2016.

[15] B. Adeoye, "The Era of Digital Technology in Teaching and Learning in Nigeria Educational Institutions. 2020," in The Roles of Technology and Globalization in Educational Transformation, Hershey, PA: IGI Global, 2020, 2020. https://doi.org/ 10.4018/978-1-5225-9746-9.ch004

[16] A. Al-Hunaiyyan, Design of Multimedia Software in Relation to Users' Culture. Ph.D thesis, University of Hertfordshire, UK, 2000. 
[17] N. Ameen and R. Willis, "Towards closing the gender gap in Iraq: understanding gender differences in smartphone adoption and use," Information Technology for Development 25 (4), pp. 660-685, 2019. https://doi.org/10.1080/02681102.2018.1454877

[18] N. Al-Huwail, S. Al-Sharhan and A. Al-Hunaiyyan, "Learning Design for a Successful Blended E-learning Environment: Cultural Dimensions. Journal of Computer Science," INFOCOMP Volume 6 - No. 4, pp. 60-69, 2007.

[19] K. Lim, Y. Nam, S. Eom, Y. Jang, D. Kim and M. Kim, "Structural Gender Differences in LMS Use Patterns among College Students," Sustainability, vol. 12, no. 11, 2020. https://doi.org/10.3390/su12114465

[20] A. Botha, D. Greunen and M. Herselman, "Mobile human-computer interaction perspective on mobile learning. 10.13140/RG.2.1.2274.3126," in 6th Annual International Conference on Computing and ICT Research (ICCIR 10), 21-24 October 2010, Kampala, Uganda, 2010.

[21] F. Dashti and A. Aldashti, "EFL College Students' Attitudes towards Mobile Learning," International Education Studies, vol. 8, no. 8, pp. 13-20, 2015. https://doi.org/10.5539/ ies.v8n8p13

[22] L. Alfarani, "Influences on the Adoption of Mobile Learning in Saudi Women Teachers in Higher Education," International Journal of Interactive Mobile Technologies. iJIM, vol. 9, no. 2, pp. 58-62, 2015. https://doi.org/10.3991/ijim.v9i2.4411

[23] A. Nassuora, "Students Acceptance of Mobile Learning for Higher Education in Saudi Arabia," International Journal of Learning Management Systems, vol. 1, no. 1, pp. 1-9, 2013. https://doi.org/10.12785/ijlms/010101

[24] M. Asplund, "Mobile learning and achievement goal orientation profiles," in Proceedings of the 10th International Conference on Mobile Learning, 28 February to 2 March 2014 , Madrid, 2014

[25] D. Kim, D. Rueckert, D. J. Kim and D. Seo, "Students' perceptions and experiences of mobile learning," Language Learning \& Technology, 17(3), p. 52-73, 2013.

[26] M. Drolia, E. Sifaki, S. Papadakis and M. Kalogiannakis, "An Overview of Mobile Learning for Refugee Students: Juxtaposing Refugee Needs with Mobile Applications' Characteristics," Challenges,11(2),31, pp. 1-14, 2020. https://doi.org/10.3390/challe 11020031

[27] N. Vyas and V. Nirban, "Students' Perception on the Effectiveness of Mobile Learning in an Institutional Context," International Association of Research in Foreign Language Education and Applied Linguistics ELT Research Journal 2014, 3(1), pp. 27-36, 2014.

[28] A. Moura and A. Carvalho, "Mobile phone appropriation and pedagogical mediation by students in educational contexts," in In MoLeNet: Mobile Learning Conference - Research papers, London, 2010.

[29] T. Goh, "Exploring Gender Differences in SMS-Based Mobile Library Search System Adoption," Educational Technology \& Society, 14 (4), p. 192-206, 2011.

[30] N. Baron and E. Campbell, " Gender and mobile phones in cross-national context," Language Sciences 34 (2012), p. 13-27, 2012. https://doi.org/10.1016/j.langsci.2011.06.018

[31] S. M. Al-Oteawi, "The perceptions of administrators and teachers in utilising information technology in instruction, administrative work, technology planning and staff development in Saudi Arabia," Doctoral dissertation, Ohio University, Ohio, 2002.

[32] S. Al-Sharhan, A. Al-Hunaiyyan and H. Al-Sharrah, "A new efficient blended e-learning model and framework for k12 and higher education: Design and Implementation Success Factors," in 2010 fifth international conference, 2010. https://doi.org/10.1109/ICDIM.2010. $\underline{5664642}$

[33] E. W. Baker, S. S. Al-Gahtani and G. S. Hubona, "The effects of gender and age on new technology implementation in a developing country: Testing the theory of planned behavior (TPB)," Information Technology \& People, vol. 20, no. 4, p. 352-375, 2007. https://doi.org/ $\underline{10.1108 / 09593840710839798}$ 
[34] T. Alasmari, "Mobile learning technology acceptance among Saudi higher education students, Diss. Abstr.," International Journal of Humanities and Social Science, 2018.

[35] A. Al-Kandari, A. Al-Hunaiyyan and R. Alhajri, "The Influence of Culture on Instagram Use,” Journal of Advances in Information Technology, vol. 7, no. 1, pp. 54-57, 2016. https://doi.org/10.12720/jait.7.1.54-57

[36] E. Georgieva, A. Smrikarova and T. Georgieva, "Evaluation of mobile learning system," Procedia Computer Science, vol. 3, p. 632-637, 2011. https://doi.org/10.1016/j.procs. 2010.12.106

[37] J. Zhang, D. Burgos and S. Dawson, "Advancing open, flexible and distance learning through learning analytics," Distance Education, 40:3, pp. 303-308, 2019. https://doi.org/ $\underline{10.1080 / 01587919.2019 .1656151}$

[38] A. K. Alhazmi and A. A. Rahman, "Facebook in Higher Education: Students' Use and Perceptions," AISS: Advances in Information Sciences and Service Sciences, vol. 5, pp. 32 - 41, 2013.

[39] S. Papadakis, "Apps to Promote Computational Thinking Concepts and Coding Skills in Children of Preschool and Pre-Primary School Age," in Mobile Learning Applications in Early Childhood Education, IGI Global, 2020, pp. 101-121. https://doi.org/10.4018/978-17998-1486-3.ch006

[40] S. Papadakis, "Robots and Robotics Kits for Early Childhood and First School Age," International Journal of Interactive Mobile Technologies, vol. 14, no. 18, pp. 34-56, 2020. https://doi.org/10.3991/ijim.v14i18.16631

[41] D. Jackson, "Instagram vs Facebook: Which Is Best for Your Brand," 2015. [Online]. Available: http://sproutsocial.com/insights/instagram-vs-facebook/.

[42] M. Kalogiannakis and S. Papadakis, "An evaluation of Greek educational Android apps for preschoolers.," in Proceedings of the 12th Conference of the European Science Education Research Association (ES ERA), Research, Practice and Collaboration in Science Education, Dublin, 2017.

\section{Authors}

Dr. Ahmed Al-Hunaiyyan is a faculty member in the Department of Computer and Information Systems at the College of Business Studies, PAAET, Kuwait. He earned his Ph.D. in the field of Computer Science, specialising in multimedia interface design, from Hertfordshire University, UK. As of working experience, he participated in various academic institutions, Al-Ain University, U.A.E., Waubonsie College, USA, Hertfordshire University, UK, Public Authority for Applied Education and Training (PAAET), Kuwait, Gulf University for Science and Technology (GUST), and Kuwait University. Email: aa.alhunaiyyan@paaet.edu.kw

Dr. Rana Alhajri is a faculty member in the Computer Science Department at the Higher Institute of Telecommunication and Navigation, PAAET, Kuwait. She earned her Ph.D. in the field of Computer Science from Brunel University, United Kingdom. Dr. Alhajri's research interests include multimedia in education; mobile learning; eLearning; human-computer interaction; software design; usability; cultural issues related to information technology, and Individual differences in Designing Web Based Instructions. Email: rana_alhajri@yahoo.com

Dr. Salah Al-Sharhan is the Dean of the School of Business and Information Technology, College of North Atlantic, Qatar. He is a member of the Machine Intelligence Research Labs (MIR). He earned his Ph.D. in Systems Design Engineering 
with an emphasis on Computational Intelligence from the University of Waterloo, Canada, in 2002. Email: salah.alsharhan@cna-qatar.edu.qa

Dr. Bimba Andrew Thomas: He received a bachelor's degree in electrical and electronics engineering in 2006, a master's degree in Computer Science (Artificial Intelligence) in 2014, and a Ph.D. in Computer Science (Artificial Intelligence) University of Malaya. His research interests include a cognitive knowledge base, natural language processing, artificial intelligence in education, machine learning, and computer-human interaction. Email: drbimbaphd@gmail.com

Article submitted 2021-01-20. Resubmitted 2021-02-28. Final acceptance 2021-02-28. Final version published as submitted by the authors. 